\title{
Trinidadian women's knowledge, perceptions, and preferences regarding cesarean section: How do they make choices?
}

This article was published in the following Dove Press journal:

International Journal of Women's Health

8 November 2010

Number of times this article has been viewed

\section{K Mungrue \\ C Nixon \\ Y David \\ D Dookwah \\ $S$ Durga \\ K Greene \\ $\mathrm{H}$ Mohammed}

Faculty of Medical Sciences, Department of Paraclinical Sciences, Public Health \& Primary Care Unit, The University of the West Indies, St Augustine, Trinidad and Tobago
Correspondence: Kameel Mungrue Faculty of Medical Sciences, Department of Paraclinical Sciences, Public Health \& Primary Care Unit, The University of the West Indies, St Augustine,

Trinidad and Tobago

Tel +868 645674 l

Email kmungrue@fms.uwi.tt
Objectives: The objective of this study is to determine the awareness of perception and attitude toward cesarean section (CS) in a high-user setting.

Design and methods: A cross-sectional design using multistage sampling methods was used to select participants from antenatal and postnatal clinics in a primary health care setting in north Trinidad. A multi-item structured questionnaire was designed and administered by in-depth interviews. Sociodemographic data and data about history of previous pregnancies and outcomes and about knowledge and perceptions of CSs were collected from women aged 16 years and older.

Results: Of the women who were eligible for entry into the study, 368 participated. However, participants chose not to respond to some questions. The majority of women $(46.2 \%)$ were found to have very little information from which to make informed decisions about selecting $\mathrm{CS}$ as the preferred choice of delivery. Their preference was significantly associated with the perception of safety (maternal or fetal death, $P=0.001$ ), difficulty (complications to mother and baby, $P=0.001)$, and pain $(P=0.001)$. Notwithstanding, persons who received information from health care professionals (odds ratio [OR], 1.9; confidence interval, 1.50-2.33) were more likely to have high or adequate levels of information about CSs. Data were analyzed using SPSS software, and ORs were calculated using logistic regression.

Conclusion: The majority of women attending antenatal and postnatal clinics in north Trinidad were not sufficiently knowledgeable about CS to enable them to make informed choices. In addition, the information obtained was from an unreliable source, emphasizing the need for information on CS to form a component of a structured antenatal education program.

Keywords: cesarean section, antenatal education, Trinidad

\section{Introduction}

The cesarean section (CS) is ranked as the number one major surgical procedure performed in the industrialized world. ${ }^{1}$ The CS rate in Trinidad increased threefold from $6.6 \%$ in $1981-1982$ to $18.4 \%$ in 2007 , despite the WHO recommendation to keep the rates between $10 \%$ and $15 \% .^{2-4}$ Previous studies on the occurrence of CS in Trinidad have focused mainly on the indications and complications associated with the procedure. However, no previous study has assessed the knowledge or attitudes of the recipients.

The knowledge recipients of a CS possess affects their ability to give informed consent to this procedure. Evidence shows that patients who are knowledgeable about their conditions are able to actively participate in shared decision-making. ${ }^{5}$ Such patients have been found to be more satisfied with their overall CS experience. ${ }^{6}$ Patients who are well informed are also more likely to have a shorter and less complicated postoperative 
recovery period. ${ }^{7}$ This results in faster bed turnovers, a reduction in the need for further interventions, and decreased costs. It is therefore necessary to measure the level of existing knowledge of CS among women of childbearing age in Trinidad, particularly as the rate of CS has tripled.

The perceptions surrounding CS may have a significant role in the willingness to consent to such a procedure. These perceptions are driven by the information women receive from diverse sources, which may vary in their accuracy and reliability. Failure to ensure patients receive accurate information may result in some women refusing a $\mathrm{CS}$, which may be necessary to prevent both maternal and fetal risks. Culture and beliefs can also significantly influence the attitude toward CS. Aziken et $\mathrm{al}^{8}$ showed that culturally biased misconceptions about CS were the main reason for a number of patients refusing this procedure regardless of its necessity. Although it is important to determine patients' knowledge of $\mathrm{CS}$, it is also important to access their attitudes and beliefs.

Health care providers are obligated to provide patients with information about procedures before obtaining consent, as recommended by the guidelines of the Royal College of Obstetricians and Gynaecologists. ${ }^{9}$ For consent to be obtained, it is necessary that the person making the decision has knowledge and understands the procedure, is mentally and legally competent, is provided with alternative choices, and makes the decision voluntarily. Health care providers also have a responsibility to correct misconceptions that women may have of CS, especially if they are culturally biased and perpetuated over time.

There are no published studies on the extent of awareness of CS among women of childbearing age in Trinidad. This is the first study of its kind to be undertaken. The evidence is necessary to inform the quality of overall clinical care delivered to patients. The study can also provide baseline data on the level of existing knowledge of CS, which can be used as a platform to raise awareness among pregnant women about the different methods of delivery and thereby empowering women to make informed choices.

The study therefore investigated the level of knowledge, attitudes, and perceptions about CS among women of childbearing age attending primary health care facilities in north Trinidad.

\section{Methods}

We used a cross-sectional study design. The source population was all women presenting for antenatal and postnatal care in a primary care setting. Participants were selected using a multistage sampling technique. In the first instance, primary health care facilities were selected using cluster sampling methods. At each facility selected, systematic sampling was used to select participants. Participants selected were invited to participate in the study. Investigators explained the purpose and benefits of the study using a standardized letter of communication, and participants were allowed a question and answer period before consent for participation was obtained. Participants who were already diagnosed of HIV/AIDS were excluded from the study.

A 26-item structured questionnaire was designed, pretested, and administered by interview to all consenting participants. Details of the themes from which the items in the questionnaire were formulated are shown in Table 1. The score is the sum of 10 variables created by using a simple dichotomous scale $($ yes $=1 /$ no $=0)$. Scores were not constructed in reference to an absolute gold standard, but rather were used for their relative values as simple tools in the analysis of women's knowledge of CS. The knowledge section of the questionnaire consisted of 10 items; a score of 0-2 was defined as none, 3-5 as low, 6-8 as adequate, and 8-10 as high. The interview was conducted in a secluded area of the clinic to ensure privacy and confidentiality, just prior to the physician consultation.

Data collected were analyzed using SPSS software (version 15; SPSS Inc, Chicago, IL). We used logistic regression to generate odds ratios (ORs) where appropriate, and a $P$ value of 0.05 was set as the level of significance. All other variables were reported as means and proportions. Ethical approval for the study was obtained from the University of the West Indies ethics committee.

\section{Results}

Three hundred sixty-eight women, who were eligible for entry into the study, participated in this study. However, some women preferred not to respond to some questions. The characteristics of the sample are summarized in Table 2.

The majority of participants $(131,34.6 \%)$ were younger than 25 years; however, there were a surprising number of women $(48,13 \%)$ who were aged 51 years and older. In Trinidad

Table I Structure of questionnaire listing the various themes constituting the various items

Structure of questionnaire by themes
Sociodemographic characteristics: Name, age, and address
Socioeconomic power: Level of education and employment
Characteristics of previous pregnancy and delivery history: Nulliparity,
gravidity, birth history, previous normal birth, and previous CS
How would you rate your previous CS experience?
Is attempting vaginal delivery easier or more difficult?
Knowledge: Indications, risk, benefits, and pain
Ability to discuss care with physician and role of the physician
Choice of mode of delivery
Vaginal birth after CS
Source of information: How and where did you get information?

Abbreviation: CS, cesarean section. 
Table 2 Sample characteristics of participants selected from antenatal and postnatal clinics in a primary care setting

\begin{tabular}{|c|c|}
\hline Sample characteristic $(N=368)$ & n (\%) \\
\hline \multicolumn{2}{|l|}{ Age group (years) } \\
\hline $16-20$ & 43 (II.7) \\
\hline $21-25$ & $88(23.9)$ \\
\hline $26-30$ & $70(19.0)$ \\
\hline $31-35$ & $54(14.7)$ \\
\hline $36-40$ & $27(7.3)$ \\
\hline $4 I-45$ & $20(5.4)$ \\
\hline $46-50$ & $17(4.6)$ \\
\hline $51+$ & $48(13.0)$ \\
\hline No response & I (0.03) \\
\hline \multicolumn{2}{|l|}{ Education } \\
\hline Primary school & $66(17.9)$ \\
\hline Secondary school & $177(48.1)$ \\
\hline University & $54(14.7)$ \\
\hline Technical/trade/skills training & $62(16.8)$ \\
\hline Others (vocational, etc) & $7(1.9)$ \\
\hline No response & $2(0.5)$ \\
\hline \multicolumn{2}{|l|}{ Employment } \\
\hline Yes & $194(52.7)$ \\
\hline No & I7| (46.5) \\
\hline No response & $3(0.8)$ \\
\hline \multicolumn{2}{|l|}{ Pregnant } \\
\hline Yes & $79(21.5)$ \\
\hline No & $289(78.5)$ \\
\hline \multicolumn{2}{|l|}{ Gravidity } \\
\hline Nulligravida & $20(5.4)$ \\
\hline Primigravida & $82(22.3)$ \\
\hline Multigravida & $209(56.8)$ \\
\hline Grand multigravida & $57(15.5)$ \\
\hline \multicolumn{2}{|l|}{ Parity } \\
\hline Nullipara & $55(14.9)$ \\
\hline Primipara & $109(29.6)$ \\
\hline Multipara & $175(47.6)$ \\
\hline Grand multipara & $29(7.9)$ \\
\hline \multicolumn{2}{|l|}{ Previous CSs } \\
\hline Yes & $53(14.4)$ \\
\hline No & $315(85.6)$ \\
\hline
\end{tabular}

Abbreviation: CS, cesarean section.

and Tobago, there is state-funded universal primary, secondary, and tertiary education; therefore, high levels of education were expected. Employment status was approximately evenly distributed. Seventy-nine (25.1\%) participants were pregnant at the time of the study, and 55 (14.9\%) were nulliparous. The CS rate adjusted for women with a previous pregnancy was $15.1 \%$, which was below the rate reported in $2007 .{ }^{3}$ When participants were asked for their preference of delivery, ie, either CS or vaginal delivery, only $6.8 \%$ of the respondents expressed a preference for CS. However, participants who had a previous CS were more likely to prefer CS than a vaginal delivery (OR, 3.4; 95\% confidence interval [CI]: 1.58-7.24).

The majority of the participants had a low level of knowledge about CS (Table 3). An association was found between the level of knowledge of CS and the educational level of
Table 3 The distribution of the level of knowledge on CS in the study sample

\begin{tabular}{ll}
\hline Level of information & $\mathbf{n}(\%)$ \\
\hline High & $30(8.1)$ \\
Adequate & $111(30.2)$ \\
Low & $170(46.2)$ \\
None & $57(15.5)$ \\
Total & $368(100)$ \\
\hline
\end{tabular}

respondents. Respondents who had the highest score for level of knowledge also had the highest level of education (analysis of variance, $F=4.6 ; P=0.001)$. Likewise, respondents who were categorized as "none", ie, no knowledge of CS, had the lowest level of education. Participants who had a previous CS also did better than those who did not. An association also existed between the respondent's personal preference and the amount of information they had. Those with a preference for CSs had adequate or high levels of knowledge of CS (OR, 1.8; 95\% CI: $1.28-2.45$ ).

Participants were asked to indicate on what basis they would favor a CS to a vaginal delivery. Most participants (44\%) favoring CS believed that they were just as safe as in the case of a vaginal delivery. On the other hand, those who favored a vaginal delivery overwhelmingly believed that $\mathrm{CS}$ was more dangerous $(62.5 \%)$. When asked about the difficulty with labor, the majority $(84.0 \%)$ of the participants preferring CS thought it would be easier than a vaginal delivery. On the other hand, $57.8 \%$ of participants who favored a vaginal delivery agreed that it was more difficult than a CS. Most women (60.0\%) who favored a CS believed it was less painful, and $55.9 \%$ of women who favored a vaginal delivery believed CS was more painful.

The main source of information about CS was predominantly a friend or relative (50\%), followed by the mass media (28.5\%), eg, tabloids, television, radio. Health care professionals $(19 \%)$ and other sources $(2.5 \%)$ ranked the lowest. We tested whether the source of information was associated with the level of knowledge and found a strong association for each of the following categories: a layperson $(P=0.001)$, the media $(P=0.001)$, or a health care professional $(P=0.001)$. In other words, a respondent receiving information from the mass media (OR, 2.1; 95\% CI: 1.69-2.70) or a health care professional (OR, 1.9; 95\% CI: 1.50-2.33) was more likely to have high or adequate levels of knowledge. Participants whose source of information was a layperson were more likely to be ranked in the category of a low level of knowledge (OR, 1.7; 95\% CI: 1.34-2.22). Also, participants who had a CS were more likely to receive their information from a health care provider (OR, 3.4; 95\% CI: 2.35-4.93). On the other hand, participants who did not have a CS were more 
likely to receive their information from a friend or relative (OR, 2.0; 95\% CI: 1.35-3.095).

Of the $14.4 \%$ (53) of the participants who had a previous CS, $83 \%$ had $1 \mathrm{CS}, 11.3 \%$ had $2 \mathrm{CSs}$, and $5.7 \%$ had 3 CSs. Of all reported CSs, $90.6 \%$ were performed in a public health care institution. Among all participants, only $1(1.9 \%)$ requested a CS while 33 (62.3\%) indicated that the decision was made by the attending physician. Further, $66.7 \%$ of all the CS performed was emergency procedures. There was no significant relationship between the type of CS, ie, emergency or elective, and the amount of information conveyed to the participant $(P=0.824)$. When participants were asked how they would like to be informed about CS, $94.9 \%$ indicated they would like the opportunity to have a question and answer interaction with their doctor. In addition, $84.6 \%$ also indicated they would read the provided information about $\mathrm{CS}$ before the procedure.

Although the majority of participants $(93.5 \%)$ indicated a preference for a vaginal delivery, 93.5\% indicated that they would agree to a CS if it was necessary to protect their baby's health. When asked about CS as an option to protect their own health, $90.8 \%$ agreed to the procedure. However, $72.8 \%$ indicated they would be offended if they received an unnecessary CS. Finally, a large percentage of participants (70.1\%) believed that following a CS, vaginal delivery for the next birth was possible.

\section{Discussion}

An overwhelming majority of women in this study preferred vaginal delivery $(93.2 \%)$ to CS $(6.8 \%)$. This preference may be due to women's beliefs that CSs are more dangerous (59.0\%), more difficult (52.2\%), and more painful (51.6\%) than vaginal deliveries. These findings concur with those of a Chilean study in which approximately $78 \%$ of women preferred vaginal deliveries. ${ }^{10}$ Such findings provide strong evidence that patient preference is unlikely to be the most significant factor driving the increasing CS rate.

The majority of those preferring vaginal deliveries held the view that CSs were more difficult, dangerous, and painful. For women who preferred CSs, both modes of delivery were believed to be equally safe. Similar findings were reported in a study by Angeja et $\mathrm{al}^{10}$ in which it was also found that these perceptions were the most important factors in determining women's decision to have a CS. These findings emphasize the need for health professionals to educate patients as to the actual risks that are associated with either mode of delivery.

More women (72.8\%) stated that they would be offended if they underwent a CS that was later found to be unnecessary. This could be due to the desire to avoid the associated risks with the operative procedure and the previously mentioned fears of pain or difficulty. In Australia, Fenwick et al ${ }^{11}$ highlighted the importance of women working with their bodies to achieve a vaginal birth, which, for them, was considered an integral part of being a woman and mother. When making recommendations for a CS, medical professionals should therefore consider these issues.

Among women who preferred a vaginal delivery, 93.5\% would accept having a CS to protect their baby's health while 90.6\% would also accept a CS in order to protect their own health. This demonstrates that women would not rigidly adhere to a preferred method of delivery. It is evident that once women are well informed as to any risks arising during pregnancy or labor, they would be willing to set aside their preferences and make an informed decision to have a CS. These findings underscore the need for effective doctor-patient communication.

The CS rate was $14.4 \%$, which was marginally lower than that previously reported. Women who had a previous CS were 3.4 times more likely to prefer a CS over a vaginal delivery in a future pregnancy than women who have never had a CS. They had high or adequate levels of information about $\mathrm{CS}$, of which the main source was health care professionals. A factor contributing to their decision to have another CS may be attributed to their experience being satisfactory. High levels of satisfaction with the procedure influences CS as an acceptable mode of delivery. Better-informed patients are able to participate more fully in the decision-making process. ${ }^{5,6}$ In addition, the level of information that these women had may also have contributed to their degree of satisfaction. This emphasizes the important contribution of patient education, particularly from health professionals to the overall clinical care that patients experience.

We found that a large proportion (33, 62.3\%) of women did not participate in the decision-making process and accepted the decision for a CS by the attending physician. This finding parallels the findings of Levinson et al ${ }^{12}$ in Canada, who found that half of the respondents (52\%) preferred to leave the final decision to their physicians. This is also consistent with the findings of Deber et a ${ }^{13}$ who found that the majority of patients wished physicians to do the "problem-solving tasks", which include using information to make a diagnosis. The comprehensive care movement and quality assurance systems are leading toward more efficient patient-centered care. ${ }^{14}$ It is therefore imperative that health care providers engage women in a meaningful way to use the information that they possess to make shared decisions, which the client is ultimately satisfied with. 
A large proportion of participants described themselves as having very little information $(46.2 \%)$ about CSs. The information that they did acquire was sourced mainly from family and friends (50\%) with little input from health care providers. It is therefore evident that not only are women deprived of information, but also the information that they do access is not from a reliable, evidence-based source. Health professionals need to ensure that the information given to women is accurate and imparted at a level that is appropriate to the women concerned. In our setting, this can be easily done at the first booking and supported by other forms of communications. This will empower women to participate in decision-making and enable them to participate meaningfully in the birth of their babies. ${ }^{15}$

Further, a majority of participants indicated that they would question their doctor (93.8\%) and read about CS (92.4\%) before giving consent to this procedure. This suggests that women have an interest in acquiring additional accurate information about their condition. It can be further deduced that women value doctors as a reliable source of information. All pregnant women need to have full knowledge of a CS, whether indicated or not. ${ }^{15} \mathrm{~A}$ structured antenatal education program for childbirth and parenthood is strongly recommended for pregnant women and their partners.

Trinidad has a two-tier system of health care: a public health care system, which is free but often inundated, and a private fee-for-service care, which tends to be more organized. The majority of the population uses the public health care system. Thus, the major limitation of the study was that the sample was taken from women attending public health care facilities and therefore is not representative of the wider population, particularly women who seek private fee-for-service health care. Further studies to compare the findings of this study with those who seek care elsewhere would provide invaluable information in developing policy and implementation strategies.

In conclusion, women in Trinidad and Tobago are not well informed about CS. However, most are still in favor of CSs if it is necessary to protect their health or that of their infant. In addition, we provide evidence for the need for accurate information to be readily available to all women. It is also evident that information alone was not the only factor but engagement of the physician in the decision-making

International Journal of Women's Health

\section{Publish your work in this journal}

The International Journal of Women's Health is an international, peerreviewed open-access journal publishing original research, reports, reviews and commentaries on all aspects of women's healthcare including gynecology, obstetrics, and breast cancer. Subject areas include: Chronic conditions (migraine headaches, arthritis, osteoporosis); process was also essential. Thus, it is not only important that health professionals proactively educate all pregnant women but also that patients are encouraged to use this information to participate more actively in their care.

\section{Disclosure}

All authors declare no conflict of interest or competing interests under the following headings: a) financial ties; b) academic commitments; c) personal relationships; d) religious beliefs; e) institutional affiliation.

\section{References}

1. Petrou S, Henderson J, Glazener C. Economic aspects of caesarean section and alternative modes of delivery. Best Pract Res Clin Obstet Gynaecol. 2001;15(1):145-163.

2. Ramsewak S, Roopnarinesingh S. An analysis of caesarean sections in a teaching hospital. West Indian Med J. 1986;35(1):23-26.

3. The Ministry of Health - Trinidad and Tobago. Trinidad and Tobago Annual Hospital Utilization Report, 2007. Port-of-Spain, Trinidad: The Ministry of Health - Trinidad and Tobago; 2007.

4. Rozemburg P. Evaluation of the caesaerian section rate: a necessary progress in obstetrics. J Gynecol Obstet Biol Reprod (Paris). 2004; 33(4):279-289.

5. Coulter A, Parsons S, Askham J. Where Are the Patients in DecisionMaking About Their Own Care? Copenhagen, Denmark: WHO Regional Office for Europe; 2008.

6. Mould TA, Chong S, Spencer JA, Gallivan S. Women's involvement with the decision preceding their caesarean section and their degree of satisfaction. Br J Obstet Gynaecol. 1996;103(11):1074-1077.

7. Klein-Fedyshin M, Burda ML, Epstein BA, Lawrence B. Collaborating to enhance patient education and recovery. J Med Libr Assoc. 2005; 93(4):440-445.

8. Aziken M, Omo-Aghoja L, Okonofua F. Perceptions and attitudes of pregnant women towards caesarean section in urban Nigeria. Acta Obstet Gynecol Scand. 2007;86(1):42-47.

9. National Collaborating Centre for Women's and Children's Health. Caesarean Section: Clinical Guideline. London: RCOG Press; 2004.

10. Angeja AC, Washington AE, Vargas JE, Gomez R, Rojas I, Caughey AB. Chilean women's preferences regarding mode of delivery: which do they prefer and why? BJOG. 2006;113(11):1253-1258.

11. Fenwick J, Gamble J, Hauck Y. Believing in birth - choosing VBAC: the childbirth expectations of a self-selected cohort of Australian women. J Clin Nurs. 2007;16(8):1561-1570.

12. Levinson W, Kao A, Kuby A, Thisted RA. Not all patients want to participate in decision making. A national study of public preferences. J Gen Intern Med. 2005;20(6):531-535.

13. Deber R, Kraetschmer N, Irvine J. What role do patients wish to play in treatment decision making? Arch Intern Med. 1996;156:1414-1420.

14. Formicola AJ, Myers R, Hasler JF, et al. Evolution of dental school clinics as patient care delivery centers. J Dent Educ. 2008;72 Suppl 2:110-127.

15. Churchill H. Caesarean Birth: Experience, Practice and History. 8th ed. Manchester, UK: Elsevier; 1997:166.
Endocrine and autoimmune syndromes; Sexual and reproductive health; Psychological and psychosocial conditions. The manuscript management system is completely online and includes a very quick and fair peer-review system. Visit http://www.dovepress.com/ testimonials.php to read real quotes from published authors. 